\title{
ETV6-ACSL6 fusion gene in myeloid neoplasms: clinical spectrum, current practice, and outcomes
}

\author{
Xia $\mathrm{Wu}^{\dagger}$, Hao Cai ${ }^{\dagger}$, Yu Qiu, Jian Li, Dao-bin Zhou and Xin-xin Cao* ${ }^{*}$
}

\begin{abstract}
Background: ETV6-ACSL6 is a fusion gene rarely reported in myeloid malignancies, and its clinical characteristics, proper treatment strategies, and effect on prognosis are poorly understood.

Results: Sixteen patients with the ETV6-ACSL6 fusion gene were identified, with a median age of 50 years. Twelve patients were male. Clinical diagnoses included chronic eosinophilic leukemia, not otherwise specified, acute myeloid leukemia, and other types of myeloproliferative and myelodysplastic disorders. Ten out of 12 patients had increased levels of eosinophils, and four out of five had increased levels of basophils in peripheral blood. Treatment with tyrosine kinase inhibitors was ineffective. The prognosis of the patients was poor, with seven patients dying within 1 year.

Conclusions: Patients with the ETV6-ACSL6 fusion gene mainly present with myeloproliferative and myelodysplastic disorders, typically with increased eosinophils and/or basophils and poor survival. Intensive therapies such as allogenic stem cell transplantation should be an initial consideration for eligible patients.
\end{abstract}

Keywords: ETV6-ACSL6 fusion gene, Chronic eosinophilic leukemia, Myelodysplastic syndrome, Myeloproliferative neoplasms

\section{Background}

Translocations involving band $12 \mathrm{p} 13$ are frequently seen in myeloid malignancies, through which ETV6 is frequently rearranged $[1,2]$. However, fusion of ETV6 with ACSL6 is very rarely reported, and the clinical characteristics, proper treatment strategies, and effect on prognosis are poorly understood [3]. The prognosis of patients with the ETV6-ACSL6 fusion gene is thought to be rather poor, with most patients surviving less than a year [3]. To expand the current knowledge of the ETV6-ACSL6 fusion gene, we reported a patient with the ETV6-ACSL6 fusion gene who presented with chronic eosinophilic leukemia, not otherwise specified (NOS), who importantly received

\footnotetext{
* Correspondence: Caoxinxin@pumch.cn

${ }^{+}$Xia Wu and Hao Cai contributed equally to this work.

Department of Hematology, Peking Union Medical College Hospital, Peking Union Medical College and Chinese Academy of Medical Sciences, Beijing, China
}

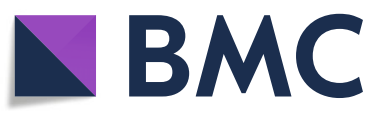

proper treatment regimens and consequently had a good prognosis. In addition, we searched the literature for all cases involving the ETV6-ACSL6 fusion gene, analyzed the data, and depicted the basic clinical characteristics, current treatment options, and outcomes of the disease.

\section{Methods}

\section{Case presentation}

A 37-year-old woman with a 16-year history of wellcontrolled ulcerative colitis presented to Peking Union Medical College Hospital with a 4-week history of continuous fever. Her maximum body temperature was $39^{\circ} \mathrm{C}$. She also had epistaxis and sweating and gradually developed disseminated 2-5 $\mathrm{mm}$ papules and nodules over the abdomen, back, and four limbs, with a 7-kg weight loss. She did not report any other symptoms. Family history indicated that three out of four of her mother's uncles and her grandmother had gastrointestinal tumors. On admission,

(c) The Author(s). 2020 Open Access This article is licensed under a Creative Commons Attribution 4.0 International License, which permits use, sharing, adaptation, distribution and reproduction in any medium or format, as long as you give appropriate credit to the original author(s) and the source, provide a link to the Creative Commons licence, and indicate if changes were made. The images or other third party material in this article are included in the article's Creative Commons licence, unless indicated otherwise in a credit line to the material. If material is not included in the article's Creative Commons licence and your intended use is not permitted by statutory regulation or exceeds the permitted use, you will need to obtain permission directly from the copyright holder. To view a copy of this licence, visit http://creativecommons.org/licenses/by/4.0/. The Creative Commons Public Domain Dedication waiver (http://creativecommons.org/publicdomain/zero/1.0/) applies to the data made available in this article, unless otherwise stated in a credit line to the data. 
her body temperature was $38.5{ }^{\circ} \mathrm{C}$; positive physical signs included disseminated reddish to brown itchy papules and nodules over the whole body, sternum tenderness, a liver $3 \mathrm{~cm}$ below the costal margin, and a spleen $1 \mathrm{~cm}$ below the costal margin. Laboratory findings were as follows. Routine blood tests showed that the white blood cell (WBC) count was $42.4 \times 10^{9} / \mathrm{L}$, the platelet count was $24 \times 10^{9} / \mathrm{L}$, and hemoglobin was $70 \mathrm{~g} / \mathrm{L}$. The peripheral blood smear revealed 53\% eosinophils and $28 \%$ basophils. The bone marrow smear revealed markedly hypercellular bone marrow with $7 \%$ myeloblasts as well as significantly increased eosinophil and eosinophil precursors at different stages (39.5\%) and increased basophil and basophil precursors (21.5\%) (Fig. 1). With the AML/MDS/MPN Sequencing Panel (Rightongene), we performed targeted amplicon sequencing on the Illumina MiSeq sequencing platform (Illumina, San Diego, CA, USA) using the patient's peripheral blood and found mutations in DNMT3A, NPM1, and GATA2; meanwhile, no abnormalities in the rest 31 genes of the panel, including PDGFRA, PDGFRB, FGFR1, and $J A K 2$ were noticed [4]. Paired-end, 101-bp RNA sequencing of over 900 fusion genes using the Illumina NextSeq 500 instrument (Illumina, San Diego, CA, USA) was performed commercially by USCI Medical Laboratory Company Limited. An out-of-frame fusion of exon 1 of ETV6 to exon 2 of ACSL6 with a fusion transcript abundance of $17.83 \%$ was identified; meanwhile, the rearrangement of other fusion genes, including FIP1L1-PDGFRA, IGH-FGFR3, TEL-FGFR3, and BCR-ABL, was not detected. Additionally, oral mucosal epithelial cells were obtained from the patient and her mother for germline testing, and the GATA2 mutation was not detected by Sanger sequencing using an ABI 3500 DX Genetic Analyzer (Applied Biosystems Inc., Foster City, CA, USA). After admission, the patient's fever persisted with a maximum body temperature of $39.0{ }^{\circ} \mathrm{C}$, while her peripheral WBC count rose to $82.1 \times 10^{9} / \mathrm{L}$. She was diagnosed with chronic eosinophilic leukemia, NOS, and standard induction chemotherapy with $100 \mathrm{mg} / \mathrm{m}^{2}$ cytarabine (subcutaneously, every
$12 \mathrm{~h}$, days $1-7$ ) and $60 \mathrm{mg} / \mathrm{m}^{2} / \mathrm{d}$ daunorubicin (intravenously, days 1-3) was used. Adverse events were not observed except for bone marrow hypocellularity and febrile neutropenia. Two weeks after the start of chemotherapy, her skin lesions diminished, and she was no longer feverish; her liver and spleen were untouchable below the costal margin. The level of eosinophils was decreased on a repeat bone marrow smear and was only slightly increased overall (5.5\%), with $0.5 \%$ myeloblasts. A test for minimal residual disease (MRD) using flow cytometry showed $0.6 \%$ myeloid precursor cells. PCR testing of ETV6-ACSL6 in bone marrow found that the rearrangement ratio was $0.019 \%$. Then, the patient received four cycles of cytarabine $(2.5 \mathrm{~g}$, by 3-h infusion every $12 \mathrm{~h}$ for 3 days), after which the ETV6ACSL6 rearrangement ratio was $0.246 \%$. Since the rearrangement ratio increase was a sign of an uncontrolled disease, the patient received a haploidentical stem cell transplantation from her mother. Fifteen months after diagnosis, which was 6 months after stem cell infusion, the patient was still in a disease-free condition. MRD tests using both flow cytometry and PCR revealed no abnormal myeloid precursor cells and an undetectable rearrangement ratio. The patient's WBC count was $6 \times 10^{9} / \mathrm{L}$, her hemoglobin level was $120 \mathrm{~g} / \mathrm{L}$, and her platelet count was $155 \times 10^{9} / \mathrm{L}$ at the last follow-up.

\section{Review of the literature}

Literature searches were performed in the Medline and Embase databases in July 2019 to retrieve articles related to the ETV6-ACSL6 fusion gene. The search items included "ETV6-ACSL6" and "TEL-ACS2". Ultimately, nine reports published between 1999 and 2016 involving 15 cases with detailed clinical data were identified and included for analysis. Detailed information for all the cases is summarized in Table 1.

\section{Results}

The ETV6-ACSL6 fusion gene was first reported by Yagasaki et al. in 1999 in three patients, with one presenting

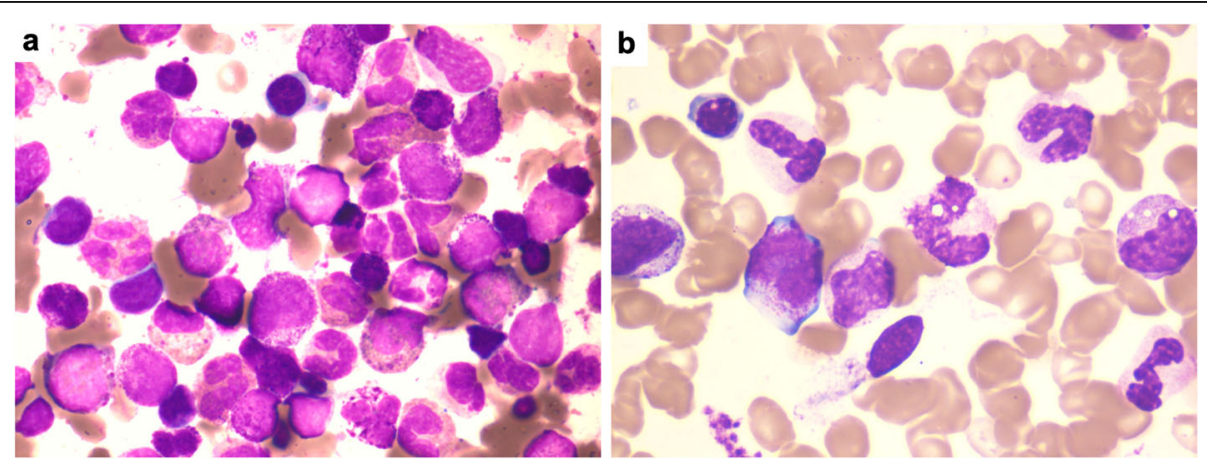

Fig. 1 Bone marrow histology in the present case. a Bone marrow smear at diagnosis $(\times 1000)$. b Bone marrow smear after haploidentical stem cell transplantation $(\times 1000)$ 


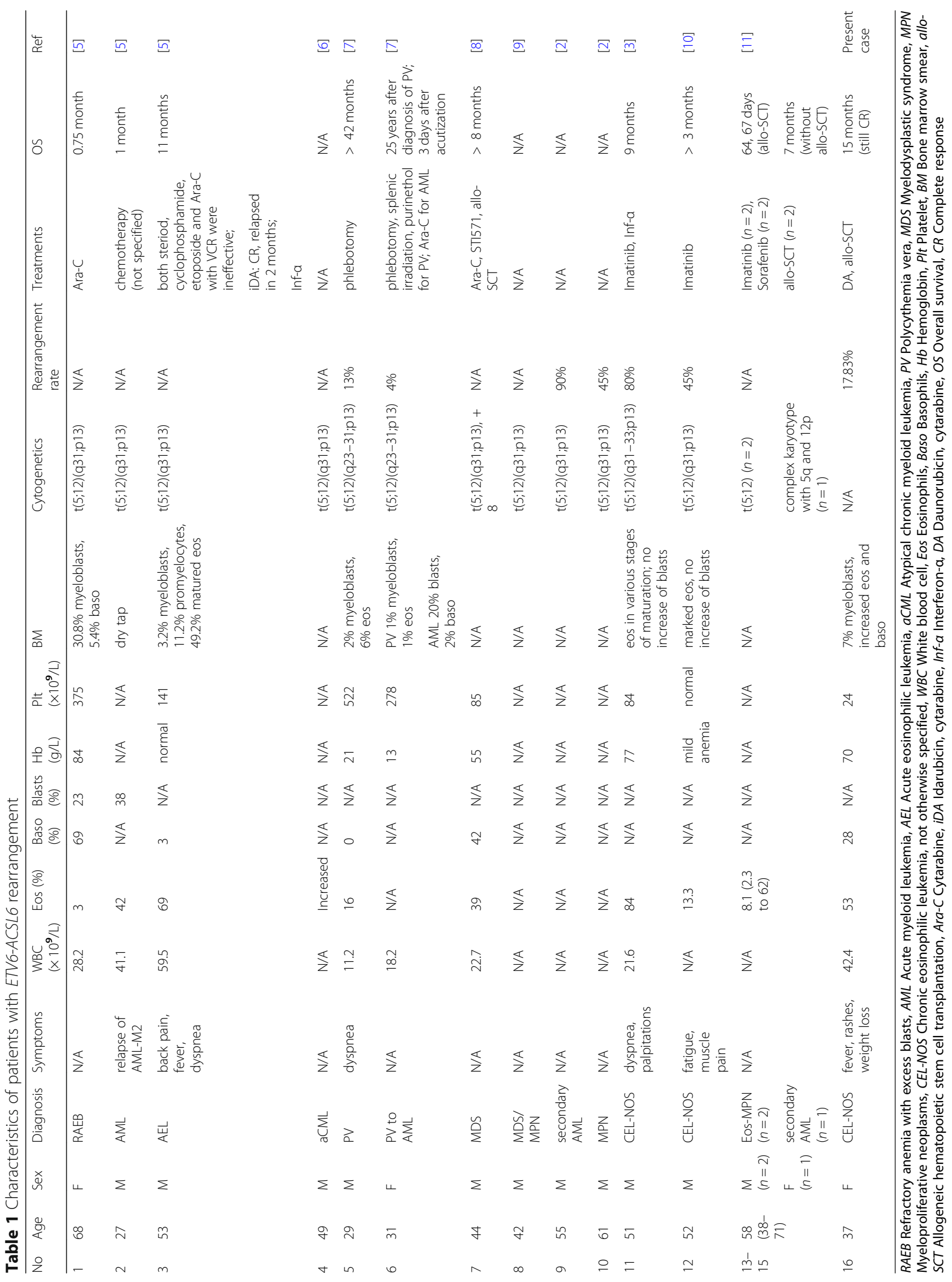


with refractory anemia with excess blasts (RAEB) with basophilia, one presenting with acute myeloid leukemia (AML), and one presenting with acute eosinophilic leukemia (AEL) [5]. Since then, the ETV6-ACSL6 fusion gene has been confirmed by either fluorescence in situ hybridization (FISH), reverse transcription polymerase chain reaction (RT-PCR), or next generation sequencing (NGS). The present case is the 16th case reported so far. The demographic characteristics, clinical symptoms and diagnosis, treatment, and outcomes of the sixteen patients are listed in Table 1 [2, 3, 511]. Twelve patients were male, with a median age of 50 years (range, 27-71 years). Patients with ETV6-ACSL6 fusion genes mainly presented with chronic eosinophilic leukemia, $\operatorname{NOS}(n=5,31 \%)$ and AML $(n=5,31 \%)$. Among the patients with AML, one had acute erythroid leukemia, one had a second relapse of AML-M2, and three had secondary AML. The diagnoses of the remaining patients included two each with MDS, MDS/MPN, and MPN. Laboratory tests at diagnosis revealed that all patients had an increased WBC $(n=8)$, with a median count of $25.5 \times$ $10^{9} / \mathrm{L}$ (range, $11.2-42.4 \times 10^{9} / \mathrm{L}$ ). Ten out of twelve patients (83\%) had increased levels of eosinophils in peripheral blood, with a median level of $42 \%$ (range, $8.1-84 \%$ ). Four out of five patients (80\%) had increased levels of basophils (median, 28\%; range, 3-69\%); 6/8 had moderate to severe anemia (75\%), while only $3 / 8$ had reduced platelet counts. Cytogenetic tests revealed $\mathrm{t}(5 ; 12)(\mathrm{q} 31 ; \mathrm{p} 13)$ in 9 of 15 patients, including one patient with +8 . The other two patients had $\mathrm{t}(5 ; 12)(\mathrm{q} 23-31 ; \mathrm{p} 13)$, and one had $\mathrm{t}(5 ; 12)(\mathrm{q} 31-33$; p13). Of the remaining three patients reported by Gosenca et al. in 2009, two had $t(5 ; 12)$, and one presented with a complex karyotype involving $5 \mathrm{q}$ and $12 \mathrm{p}$ [11]. Treatments using tyrosine kinase inhibitors were ineffective, including imatinib $(n=4)$ and sorafenib $(n=2)[3,10,11]$. Hydroxyurea was used in $58 \%$ of patients and sometimes led to temporary decreases in eosinophils and improvement of anemia and clinical symptoms [10]. Five patients received cytarabine with or without daunorubicin, and four patients received allogenic stem cell transplantation. The prognosis for patients with the ETV6-ACSL6 fusion gene was rather poor, with seven patients dying within 1 year. Only one patient with polycythemia vera survived more than 42 months [7].

\section{Discussion}

ETV6 (ETS variant 6, previously known as TEL) is a transcription factor encoded by the ETS variant 6 gene (ETV6) belonging to the ETS (E-Twenty-Six) family, which is highly expressed in early hematopoietic progenitor cells $[12,13]$. Deregulation of ETV6 involves somatic and germline fusions, deletions, and rearrangements [14, 15]. ACSL6 (Acyl-CoA synthetase long chain family member 6) encodes a long-chain acyl-CoA synthetase that catalyzes the formation of acyl-CoA from fatty acids, ATP, and CoA [16]. Different breakpoints lead to various in-frame and out-of-frame fusions of ETV6 with ACSL6, which may cause leukemogenesis $[5,10]$. A schematic of the ETV6ACSL6 fusion in the present case is shown in Fig. 2. The mechanisms by which ETV6-ACSL6 gene fusion promotes leukemogenesis remain unclear. In general, ETV6-ACSL6 fusion gene is very rare but can occur in myeloid neoplasms. Sixteen cases have been sporadically reported thus far. The incidence of the ETV6-ACSL6 fusion gene might be underestimated. Several studies reported the recurrent translocation of $\mathrm{t}(5 ; 12)(\mathrm{q} 31 ; \mathrm{p} 13)$; however, they did not

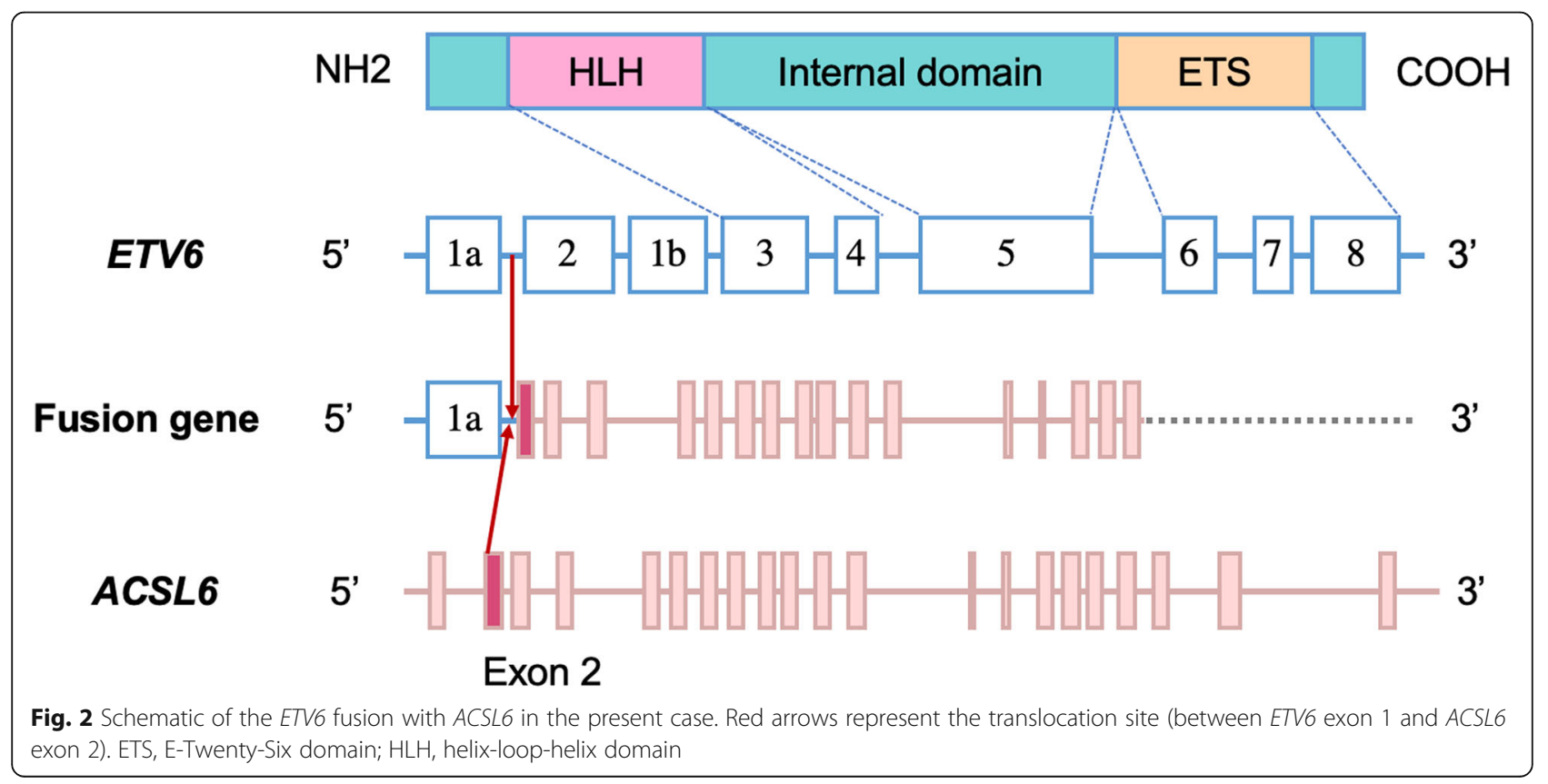


perform molecular analysis to further verify whether it contained ETV6-ACSL6 fusion [8, 17, 18].

In terms of the clinical characteristics, we found that the ETV6-ACSL6 fusion gene seemed to occur predominantly in males. The median age was 50 years, which was slightly younger than that of patients with chronic myeloid disorders [19]. Of note, all patients with the fusion gene presented with myeloid disorders, with a slightly predominance of chronic myeloid disorders. Among patients with chronic myeloid disorders, many had chronic eosinophilic leukemia, NOS, and others suffered from MDS, MDS/MPN, and MPN. In addition, we found that the majority of the patients had increased eosinophils in peripheral blood [3, 5, 7]. Additionally, our study revealed that $80 \%$ of patients also had increased basophils in peripheral blood. Therefore, an increase in eosinophils and/or basophils seems to be a representative sign of the ETV6-ACSL6 fusion gene. Nearly one-third of the patients were diagnosed with AML, of which more than half had secondary AML. In the present case, although the patient was diagnosed with chronic eosinophilic leukemia, NOS, she had a rapid progressive disease pattern with $7 \%$ myeloblasts in her bone marrow, accompanied by fever, skin rashes, and an enlarged liver and spleen. The patient would probably be unresponsive to conventional chemotherapy for CEL and may suffer from acute transformation into AML, which has a poor prognosis [20].

Overall, the prognosis of patients with the ETV6-ACSL6 fusion gene is poor. Treatment strategies are varied due to the diverse clinical presentations as well as a lack of consensus guidelines for treatment. For the cases that presented as chronic eosinophilic leukemia, NOS, several reports indicated treatment with tyrosine kinase inhibitors was attempted, and all cases turned out to be nonresponsive. Unlike ETV6-PDGFRB or other rearrangements of $P D G F R B$, which are receptor-tyrosine kinase fusion genes, the ETV6-ACSL6 fusion gene does not result in a fusion protein with constitutive tyrosine kinase activity [21]. Therefore, tyrosine kinase inhibitors are not recommended for these patients [22]. For patients presenting with acute leukemia, standardized intensive chemotherapy followed by allogenic stem cell transplantation might be successful. For the four patients who received allogenic stem cell transplantation, one died on day +67 due to the relapse of secondary AML, and one died on day +64 due to transplant complications [11]. The other two patients (Patient 7 and the present patient) survived more than 8 months and 15 months, respectively [8]. In the present case, although the patient was diagnosed with chronic eosinophilic leukemia, NOS, she experienced a rapidly progressive and severe clinical course. Hence, she received allogenic stem cell transplantation. At the 15-month follow-up, the patient was still in a disease-free condition.

\section{Conclusions}

The ETV6-ACSL6 fusion gene is extremely rare. Patients with the fusion gene mainly present with myeloproliferative and myelodysplastic disorders, typically chronic eosinophilic leukemia, NOS. The patients usually have increased eosinophils and/or basophils, and there is a very real possibility of transformation to AML. We recommend that intensive therapies should be an initial consideration for eligible patients. Meanwhile, the presence of MRD can be monitored in patients by flow cytometry as well as PCR for the ETV6-ACSL6 rearrangement ratio. In the future, clinical trials and targeted therapies are needed to modify the natural history of the disease.

\section{Abbreviations}

NOS: Not otherwise specified; WBC: White blood cell; MRD: Minimal residual disease; RAEB: Refractory anemia with excess blasts; AML: Acute myeloid leukemia; AEL: Acute eosinophilic leukemia; FISH: Fluorescence in situ hybridization; RT-PCR: Reverse transcription polymerase chain reaction; NGS: Next-generation sequencing

\section{Acknowledgements}

Not applicable.

\section{Authors' contributions}

XW and HC performed the study and drafted the manuscript. XW, HC and YQ collected the clinical data and were responsible for the molecular genetic tests. JL and DZ designed the study and revised the manuscript. XC designed and performed the study and revised the manuscript. All authors read and approved the final manuscript.

\section{Funding}

Funding was obtained from the Nonprofit Central Research Institute Fund of Chinese Academy of Medical Sciences (2019-RC-HL-001, for CXX), the CAMS Innovation Fund for the Medical Sciences (2016-12 M-1-002, for $\sqcup$ ), and the National Key Research and Development Program of China

(2016YFC0901503, for LJ).

\section{Availability of data and materials}

All literature included in the manuscript is listed in the references. Articles were identified in the Medline and Embase databases, and access to the full texts was dependent on journal and institutional constraints.

\section{Ethics approval and consent to participate}

No ethical approval was required.

\section{Consent for publication}

Consent for publication was obtained from the reported patient.

\section{Competing interests}

The authors declare no competing interests.

Received: 6 September 2019 Accepted: 21 July 2020

Published online: 28 July 2020

References

1. Slater R, Drunen E, Kroes W, Weghuis DO, van den Berg E, Smit E, et al. t (7; 12)(q36; p13) and t (7; 12)(q32; p13)-translocations involving ETV6 in children 18 months of age or younger with myeloid disorders. Leukemia. 2001;15(6):915.

2. Haferlach C, Bacher U, Schnittger S, Alpermann T, Zenger M, Kern W, et al. ETV6 rearrangements are recurrent in myeloid malignancies and are frequently associated with other genetic events. Genes Chromosom Cancer. 2012;51(4):328-37.

3. Luca-Johnson D, Ninfea JIR, Pearson L, Conant J, Bryant R, Zakai NA, et al. Myeloid neoplasms with $t(5 ; 12)$ and ETV6-ACSL6 gene fusion, potential mimickers of myeloid neoplasm with PDGFRB rearrangement: case report 
with imatinib therapy and review of the literature. Case Rep Med. 2016; 2016:8324791.

4. Cao X-X, Cai H, Mao Y-Y, Wu Q, Zhang L, Zhou D-B, et al. Next-generation sequencing-based genetic landscape and its clinical implications for Chinese acute myeloid leukemia patients. Cancer Cell Int. 2018;18(1):215.

5. Yagasaki F, Jinnai I, Yoshida S, Yokoyama Y, Matsuda A, Kusumoto S, et al. Fusion of TEL/ETV6 to a novel ACS2 in myelodysplastic syndrome and acute myelogenous leukemia with t (5; 12)(q31; p13). Genes Chromosom Cancer. 1999;26(3):192-202.

6. Cools J, Mentens N, Odero MD, Peeters P, Wlodarska I, Delforge M, et al. Evidence for position effects as a variantETV6-mediated leukemogenic mechanism in myeloid leukemias with at $(4 ; 12)(\mathrm{q} 11-\mathrm{q} 12 ; \mathrm{p} 13)$ or $\mathrm{t}(5$; 12)(q31; p13). Blood. 2002;99(5):1776-84.

7. Murati A, Adelaide J, Gelsi-Boyer V, Etienne A, Remy V, Fezoui $\mathrm{H}$, et al. t (5; 12)(q23-31; p13) with ETV6-ACSL6 gene fusion in polycythemia vera. Leukemia. 2006;20(6):1175.

8. Katsura Y, Suzukawa K, Nanmoku T, Nemoto N, Machino T, Obara N, et al. Myelodysplastic syndrome accompanied by basophilia and eosinophilia with t $(5 ; 12)(q 31 ;$ p13). Cancer Genet Cytogenet. 2007;178(1):85-8.

9. Erben P, Gosenca D, Müller MC, Reinhard J, Score J, del Valle F, et al. Screening for diverse PDGFRA or PDGFRB fusion genes is facilitated by generic quantitative reverse transcriptase polymerase chain reaction analysis. Haematologica. 2010;95(5):738-44.

10. Su RJ, Jonas BA, Welborn J, Gregg JP, Chen M. Chronic eosinophilic leukemia, NOS with t (5; 12)(q31; p13)/ETV6-ACSL6 gene fusion: a novel variant of myeloid proliferative neoplasm with eosinophilia. Human Pathol Case Rep. 2016;5:6-9.

11. Gosenca D, Erben P, Haferlach C, Schwerdtfeger R, Baurmann H, Bolz G, et al. Clinical and molecular heterogeneity of eosinophilia-associated myeloproliferative neoplasms with a translocation t (5; 12). Blood. 2009;1 14(22):4983. https://doi.org/ 10.1182/blood.V114.22.4983.4983.

12. Hock H, Shimamura A. ETV6 in hematopoiesis and leukemia predisposition. Seminars in Hematology. 2017;54(2):98-104. https://doi.org/10.1053/j. seminhematol.2017.04.005.

13. Di Paola J, Porter CC. ETV6-related thrombocytopenia and leukemia predisposition. Blood. 2019;134(8):663-7.

14. Hunger SP, Mullighan CG. Redefining ALL classification: toward detecting highrisk ALL and implementing precision medicine. Blood. 2015;125(26):3977-87.

15. Melazzini F, Palombo F, Balduini A, De Rocco D, Marconi C, Noris P, et al. Clinical and pathogenic features of ETV6-related thrombocytopenia with predisposition to acute lymphoblastic leukemia. Haematologica. 2016; 101(11):1333-42

16. Teodoro BG, Sampaio IH, Bomfim LH, Queiroz AL, Silveira LR, Souza AO, et al. Long-chain acyl-CoA synthetase 6 regulates lipid synthesis and mitochondrial oxidative capacity in human and rat skeletal muscle. $J$ Physiol. 2017;595(3):677-93.

17. Kim M, Lim J, Lee A, Park G, Kim Y, Han K, et al. A case of chronic myelomonocytic leukemia with severe eosinophilia having t $(5 ; 12)$ (q31; p13) with t (1; 7)(q10; p10). Acta Haematol. 2005;114(2):104-7.

18. Tang G, Woods LJ, Wang SA, Brettler D, Andersen M, Miron PM, et al. Chronic basophilic leukemia: a rare form of chronic myeloproliferative neoplasm. Hum Pathol. 2009:40(8):1194-9.

19. Björkholm M, Kristinsson SY, Landgren O, Goldin LR. No familial aggregation in chronic myeloid leukemia. Blood. 2013;122(3):460-1.

20. Helbig G, Soja A, Bartkowska-Chrobok A, Kyrcz-Krzemień S. Chronic eosinophilic leukemia-not otherwise specified has a poor prognosis with unresponsiveness to conventional treatment and high risk of acute transformation. Am J Hematol. 2012;87(6):643-5.

21. De Braekeleer E, Douet-Guilbert N, Morel F, Le Bris M-J, Basinko A, De Braekeleer M. ETV6 fusion genes in hematological malignancies: a review. Leuk Res. 2012;36(8):945-61.

22. Butt NM, Lambert J, Ali S, Beer PA, Cross NC, Duncombe A, et al. Guideline for the investigation and management of eosinophilia. Br J Haematol. 2017; 176(4):553-72

\section{Publisher's Note}

Springer Nature remains neutral with regard to jurisdictional claims in published maps and institutional affiliations.

Ready to submit your research? Choose BMC and benefit from:

- fast, convenient online submission

- thorough peer review by experienced researchers in your field

- rapid publication on acceptance

- support for research data, including large and complex data types

- gold Open Access which fosters wider collaboration and increased citations

- maximum visibility for your research: over $100 \mathrm{M}$ website views per year

At BMC, research is always in progress.

Learn more biomedcentral.com/submissions 